\title{
Water vapor adsorption-desorption properties of bamboo charcoals prepared by air oxidation following low temperature carbonization
}

\author{
Miki Sakuma $^{\text {a) }}$, Yoshimasa Amano ${ }^{\text {b), c), * and Motoi Machida }}{ }^{\text {b), c) }}$
}

\begin{abstract}
Bamboo charcoals were prepared by low temperature carbonization at $500{ }^{\circ} \mathrm{C}$, and subsequent treatments such as air oxidation at $180-380^{\circ} \mathrm{C}$ for the introduction of functional groups on the surface, and outgassing at $1000{ }^{\circ} \mathrm{C}$ for their removal were conducted to examine the relationship between the amount of water vapor adsorption and the surface properties of the prepared charcoals. The air oxidation treatment was effective in developing surface area and pore volume as well as surface functional groups, and the developments were in proportion to the treatment temperature. Air oxidation of the prepared charcoal at $380^{\circ} \mathrm{C}$ increased surface area from $250 \mathrm{~m}^{2} / \mathrm{g}$ to $590 \mathrm{~m}^{2} / \mathrm{g}$ and pore volume from $0.16 \mathrm{~mL} / \mathrm{g}$ to $0.31 \mathrm{~mL} / \mathrm{g}$. At a relative humidity below $50 \%$, the charcoals oxidized at $380{ }^{\circ} \mathrm{C}$ were able to adsorb approximately twice the amount of water vapor compared to those oxidized at $180^{\circ} \mathrm{C}$ and $280^{\circ} \mathrm{C}$, indicating that the water vapor adsorption depends on the surface functional groups. In a relative humidity above $50 \%$, the outgassed bamboo charcoals adsorbed a large amount of water vapor, indicating that mesopores and macropores, rather than surface functional groups, contributed to water vapor adsorption.
\end{abstract}

\section{KEYWORDS : Bamboo activated carbons, Carbonization, Air oxidation, Surface and pore structural properties, Water vapor adsorption and desorption}

\section{Introduction}

Although the waste woods generated from building demolition are generally treated by incineration or landfill as industrial wastes, alternative treatment methods are needed because of decrease in landfill sites. Many studies on the effective utilization of thinned or waste woody materials have been conducted from the viewpoint of the reuse of biomass ${ }^{1), 2)}$. Among various utilizations of waste, charcoals and activated carbons are one of the widely studied materials as an effective adsorbent for humidity control ${ }^{3)}$, water purification ${ }^{4)}$ and removal of organic pollutants ${ }^{5-7)}$ because of their multiple functions corresponding to various pore sizes.

Bamboo is abundant natural resources in Asia. Bamboo could be harvested in 3-5 cyclic years and has supplied as various products for human life. Charcoals prepared from bamboo have been noticed as superior adsorbent compared to those prepared from other woods. Although recent publications suggested the various kinds of preparation methods and the effect of gaseous or chemical activation methods on the developments of surface area and pore volume of bamboo charcoals $^{8)-10)}$, these techniques have some problems such as a heavy load to the instrument and much energy with higher temperature condition. So far, few studies have been reported on the preparation methods at low temperature and low cost with simple operation of bamboo charcoals.

One of the superior functions of charcoals is understood as humidity control, adsorbing greater amount of moisture at high humidity condition and, contrarily, desorbing the moisture at low humidity ${ }^{6), 11)-13)}$. The effect of humidity control is semipermanently maintained ${ }^{6)}$, thereby the charcoals prepared from bamboo have been widely used as a humidity control material. In general, the effect of humidity control for charcoals is evaluated by the adsorption-desorption isotherms, which represent the amount of adsorbed and desorbed humidity under the prescribed humidity circumstance at constant temperature $^{6), 11)-14)}$.

In this study, bamboo was used to obtain the superior adsorbent for the water vapor adsorption. The charcoals were prepared by carboniz- 
ing at $500{ }^{\circ} \mathrm{C}$, which was lower than the generally used carbonization temperature but was enough for the decomposition of large polymer included in the raw material ${ }^{15)}$. The air oxidation treatment under atmospheric pressure was also demonstrated to vary the surface properties of the bamboo charcoals. The relationship between the amount of water vapor adsorbed and the properties of surface nature and pore structure was also examined based on the water vapor adsorption and desorption experiments using the various prepared bamboo charcoals.

\section{Materials and Methods}

\subsection{Preparation of bamboo charcoals}

\subsubsection{Carbonization}

Moso bamboo (Phyllostachys pubescens, Aichi Prefecture, Japan) was employed as raw material. The raw bamboo was arranged as $15 \times 5 \times 2 \mathrm{~mm}$ chips and washed by boiling distilled water for 6 hours $(2$ hours $\times 3$ ) to remove impurity. Replacing the boiled water, washing was repeated three times. The bamboo chips were then dried at $110{ }^{\circ} \mathrm{C}$ overnight. Approximately $15 \mathrm{~g}$ of the bamboo chips was filled in a quartz boat and carbonized at $500{ }^{\circ} \mathrm{C}$ with heating rate of $25^{\circ} \mathrm{C} / \mathrm{min}$ under nitrogen flow using a tubular furnace. After the temperature in the furnace reached $500{ }^{\circ} \mathrm{C}$, carbonization was processed for 2 hours. Cooling the carbonized bamboo chips to room temperature, the bamboo charcoals were prepared. The prepared charcoals were referred to as BC (bamboo charcoal). The same preparation process was also conducted for non-washed bamboo chips for comparison. The bamboo charcoals obtained from the non-washed bamboo chips were donated as NW-BC (non-washed bamboo charcoals) hereafter.

The yield, $Y(\%)$, of the obtained bamboo charcoal was calculated by Eq. (1)

$$
Y=\left(\frac{W_{0}}{W_{\mathrm{L}}}\right) \times 100
$$

where $W_{0}$ and $W_{\mathrm{L}}$ were the dry weight of bamboo after and before carbonization, respectively. The bamboo charcoals were used for the experiment after grinding and arranging of the particle size in the range of $0.42-0.84 \mathrm{~mm}$.

\subsubsection{De-ashing treatment of the prepared bamboo charcoals}

Approximately $5 \mathrm{~g}$ of the sample was added into $200 \mathrm{~mL}$ of 2 $\mathrm{mol} / \mathrm{L} \mathrm{HCl}$ aqueous solution and left for 6 hours. This process was repeated two times. Afterwards, the sample was left in $46 \% \mathrm{HF}$ solution overnight. Then, the sample was washed by boiling distilled water until the $\mathrm{pH}$ no longer changed, and dried at $110{ }^{\circ} \mathrm{C}$ overnight ${ }^{16)}$. This sample was referred to as BC-DA (de-ashed bamboo charcoal).

\subsubsection{Air oxidation treatment of the prepared bamboo charcoals}

The ash of bamboo includes various elements, especially much amount of potassium, which significantly contributes to the develop- ment of surface area ${ }^{17)}$. In this study, the air oxidation treatment for the bamboo charcoals was conducted without any treatments for ash removal.

Approximately $10 \mathrm{~g}$ of bamboo charcoals was set on an alumina plate and oxidized at 180,280 and $380^{\circ} \mathrm{C}$ for 2 hours in atmospheric pressure using a muffle furnace. The bamboo charcoals were allowed to be cooled in desiccator and weighed. These samples were denoted as BC-AO- $T$ (air oxidation bamboo charcoal at $T^{\circ} \mathrm{C}$, where $T$ means the oxidized temperature).

The yield, $Y_{\mathrm{AO}}(\%)$, of the oxidized bamboo charcoal was calculated as follows.

$$
Y_{\mathrm{AO}}=\left(\frac{W_{\mathrm{AO}}}{W_{0}}\right) \times 100,
$$

where $W_{\mathrm{AO}}$ and $W_{0}$ were the dry weight of bamboo charcoals after and before oxidation, respectively.

\subsubsection{Outgassing treatment of the prepared bamboo charcoals}

Outgassing treatment was performed for the air-oxidized bamboo charcoals to remove the functional groups of the surface. This method has been widely employed for the removal of surface functional groups ${ }^{18)}$. The air-oxidized bamboo charcoals filled in a quartz boat were set in a tubular furnace and heated at $1000{ }^{\circ} \mathrm{C}$ under He flow with the flow rate of $200 \mathrm{~mL} / \mathrm{min}$ for 2 hours to eliminate the surface functional groups. The treated charcoals were cooled to the room temperature in a furnace, and the outgassing bamboo charcoals (BCAO-T-OG) were obtained.

The yield, $Y_{\mathrm{OG}}(\%)$, after outgassing treatment was calculated by

$$
Y_{\mathrm{OG}}=\left(\frac{W_{\mathrm{OG}}}{W_{\mathrm{AO}}}\right) \times 100,
$$

where $W_{\mathrm{OG}}$ was the dry weight of bamboo charcoals after outgassing treatment.

\subsection{Surface properties of the prepared bamboo charcoals}

\subsubsection{Measurement of surface area and pore volume}

The $\mathrm{N}_{2}$ gas adsorption at $-196{ }^{\circ} \mathrm{C}$ using the surface area analyzer (Beckman Coulter SA3100, Beckman Coulter) was performed to obtain the adsorption isotherms for the prepared bamboo charcoals. The results were used to determine the specific surface area, $S_{\mathrm{BET}}$ and $S_{\alpha s}$, based on the BET and the SPE methods using $\alpha_{s}$-plot, respectively, and the total pore volume, $V_{\text {total }}$, based on the amount of $\mathrm{N}_{2}$ adsorbed at relative pressure $\left(P / P_{0}\right)$ of 0.98 . Also, the micropore volume,

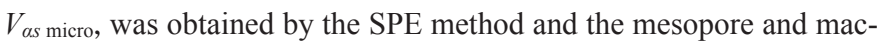
ropore volume, $V_{a s}$ meso\&macro, was estimated from the difference between total pore and micropore volume.

2.2.2 Quantitative analysis of surface functional groups on the prepared bamboo charcoals

Boehm titration method was employed to evaluate the surface functional groups for each prepared bamboo charcoal ${ }^{19)}$. Approxi- 
mately $200 \mathrm{mg}$ of the sample was added into $15 \mathrm{~mL}$ of $0.1 \mathrm{~mol} / \mathrm{L}$ $\mathrm{NaHCO}_{3}, \mathrm{NaOH}, \mathrm{HCl}$ and $0.05 \mathrm{~mol} / \mathrm{L} \mathrm{Na}_{2} \mathrm{CO}_{3}$ aqueous solutions in $100 \mathrm{~mL}$ conical flask. Each flask was agitated at $100 \mathrm{rpm}$ for 3 days at $25{ }^{\circ} \mathrm{C}$. A $5 \mathrm{~mL}$ aliquot of each sample was separately collected into a $30 \mathrm{~mL}$ flask, and the sample was titrated by $0.05 \mathrm{~mL} \mathrm{HCl}$ solution. The basic functional groups on the surface of bamboo charcoals were titrated with $\mathrm{HCl}$ and estimated as the total amount of basic functional groups based on the change in $\mathrm{HCl}$ concentration. Carboxyl groups were neutralized by only weak base of $\mathrm{NaHCO}_{3}$ solution. Lactone and carboxyl groups were done by $\mathrm{Na}_{2} \mathrm{CO}_{3}$ solution. Lactone, carboxyl and phenolic groups were done by strong base of $\mathrm{NaOH}$ solution. Each functional group could be estimated by the change in concentration for each basic solution.

\subsection{Characteristics of water vapor adsorption and desorption for the prepared bamboo charcoals}

The characteristics of water vapor adsorption and desorption were examined for each prepared bamboo charcoal. The moisture included in the bamboo charcoals was removed prior to the water vapor adsorption and desorption experiments. The bamboo charcoals were dried at $110{ }^{\circ} \mathrm{C}$ overnight, and the charcoals were allowed to be cooled in desiccator. The charcoals obtained in this process were used for the water vapor adsorption and desorption experiments. Fig. 1 showed the apparatus for the experiment in this study. Approximately $5 \mathrm{~g}$ of each prepared charcoal was set in a glass vessel, and the water vapor adsorption and desorption experiments were conducted in desiccator in which the constant humidity was kept with the saturated salt solutions of lithium, magnesium, sodium and potassium ${ }^{20), 21)}$

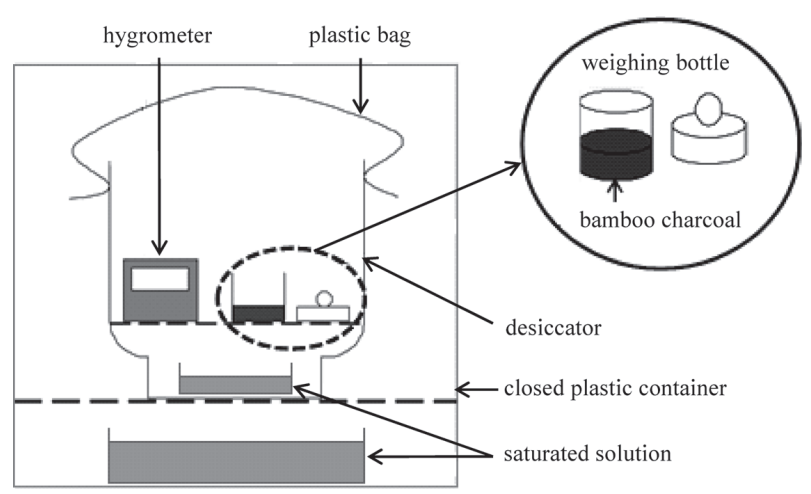

Fig. 1 Apparatus of water vapor adsorption-desorption experiment.

Table 1 Humidity control with saturated solution.

\begin{tabular}{cc}
\hline Salt & Relative humidity (\%) \\
\hline $\mathrm{LiCl}$ & $12 \pm 1$ \\
$\mathrm{MgCl}_{2}$ & $35 \pm 1$ \\
$\mathrm{Mg}\left(\mathrm{NO}_{3}\right)_{2}$ & $56 \pm 1$ \\
$\mathrm{NaCl}$ & $81 \pm 1.5$ \\
$\mathrm{KCl}$ & $90 \pm 1.5$ \\
$\mathrm{KNO}_{3}$ & $97 \pm 1.5$ \\
\hline & (data shown at $\left.23^{\circ} \mathrm{C}\right)$
\end{tabular}

(Table 1).

The adsorption-desorption isotherms of water vapor for each prepared bamboo charcoal were obtained based on the amounts of adsorption and desorption per unit weight of charcoals. It is generally accepted that the water vapor adsorption-desorption isotherms of charcoals represent the hysteresis $^{6}$. In this study, the water vapor adsorption ability for the prepared bamboo charcoals was evaluated by adsorption-desorption isotherms of water vapor obtained at 12,35 , $56,81,90$ and $97 \%$ relative humidity $(\mathrm{RH})$ at constant temperature of $23{ }^{\circ} \mathrm{C}$

\section{Results and Discussion}

\subsection{Effect of impurity removal on the surface and pore proper-} ties of the prepared bamboo charcoals

The yield, surface area and pore volume for the prepared bamboo charcoals were summarized in Table 2. The removal of impurity by washing before carbonization for bamboo chips caused approximately 8 times and 2.5 times advances of the surface area and pore volume, respectively, for the bamboo charcoals compared to the nonwashing ones. In general, the cells in bamboo are regularly lined with innumerable pores on the surface ${ }^{22)}$. The enhancements of surface area and pore volume would be attributed to the degree of the release of volatile components in the carbonization process. Also, it is possible that the structural components such as hemicelluloses, cellulose and lignin in the bamboo chips were hydrolyzed by washing, causing the elution of these components from the chips. The promotion of release of volatile components would be due to the swelling of bamboo chips by washing in boiling water, enhancing the discharge of volatile matters from the pore of bamboo charcoals in the nitrogen flow, i.e., the ejector effect would result in the developments of both surface area and pore volume.

\subsection{Surface and pore properties of the air oxidation bamboo} charcoals

Table 3 showed the primary elements and their contents in ash in-

Table 2 Yield and surface properties of BC and NW-BC carbonized at $500{ }^{\circ} \mathrm{C}$ in $\mathrm{N}_{2}$ flow.

\begin{tabular}{ccccccc}
\hline Sample & $\begin{array}{c}\text { Yield } \\
(\%)\end{array}$ & $\begin{array}{c}S_{\text {BET }} \\
\left(\mathrm{m}^{2} / \mathrm{g}\right)\end{array}$ & $\begin{array}{c}S_{\alpha s} \\
\left(\mathrm{~m}^{2} / \mathrm{g}\right)\end{array}$ & $\begin{array}{c}V_{\text {total }} \\
(\mathrm{mL} / \mathrm{g})\end{array}$ & $\begin{array}{c}V_{\text {as micro }} \\
(\mathrm{mL} / \mathrm{g})\end{array}$ & $\begin{array}{c}V_{\text {as meso\&macro }} \\
(\mathrm{mL} / \mathrm{g})\end{array}$ \\
\hline NW-BC & 29.8 & 31 & 29 & 0.067 & 0.000 & 0.067 \\
BC & 23.4 & 250 & 250 & 0.160 & 0.083 & 0.077 \\
\hline
\end{tabular}

NW-BC: Non-Washed Bamboo Charcoal, BC: Bamboo Charcoal, $\alpha s: \alpha_{s^{-}}$ plot, micro: micropore, meso \& macro: mesopore and macropore

Table 3 Ash composition of BC.

\begin{tabular}{ccccccc}
\hline Sample & $\mathrm{K}$ & $\mathrm{Ca}$ & $\mathrm{Si}$ & $\mathrm{P}$ & $\mathrm{Cl}$ & $\mathrm{S}$ \\
\hline BC & 2.36 & 0.05 & 0.02 & 0.08 & 0.05 & 0.03 \\
\hline \multicolumn{2}{l}{ BC: Bamboo Charcoal } \\
\end{tabular}


Table 4 Surface properties of BC series.

\begin{tabular}{ccccccccc}
\hline \multirow{2}{*}{ Sample } & \multirow{2}{*}{$\begin{array}{c}S_{a s} \\
\left(\mathrm{~m}^{2} / \mathrm{g}\right)\end{array}$} & $\begin{array}{c}V_{\text {total }} \\
(\mathrm{mL} / \mathrm{g})\end{array}$ & $\begin{array}{c}R_{\text {micro }} \\
(\%)\end{array}$ & & & \multicolumn{3}{c}{ Surface functional group (meq./g) } \\
\cline { 5 - 8 } & & & & Carboxylic & Lactonic & Phenolic & 0.64 \\
BC & 250 & 0.160 & 51.8 & 0.02 & 0.00 & 0.23 \\
BC-AO-280 & 327 & 0.161 & 57.1 & 0.13 & 0.00 & 0.67 & 0.00 \\
\hline
\end{tabular}

BC: Bamboo Charcoal, BC-DA-AO-280: Bamboo Charcoal De-Ashed and Air-Oxidized at $280{ }^{\circ} \mathrm{C}, \mathrm{BC}-\mathrm{AO}-280$ : Bamboo Charcoal Air-Oxidized at $280{ }^{\circ} \mathrm{C}$, as: $\alpha_{s}$-plot, $R_{\text {micro }}$ micropore volume ratio

Table 5 Influence of air oxidation at various temperatures and outgassing $1000{ }^{\circ} \mathrm{C}$ on structural and surface properties of $\mathrm{BC}$ series.

\begin{tabular}{|c|c|c|c|c|c|c|c|c|c|c|}
\hline \multirow{2}{*}{ Sample } & \multirow{2}{*}{$\begin{array}{l}\text { Yield } \\
(\%)\end{array}$} & \multirow{2}{*}{$\begin{array}{c}S_{\mathrm{BET}} \\
\left(\mathrm{m}^{2} / \mathrm{g}\right)\end{array}$} & \multirow{2}{*}{$\begin{array}{c}S_{a s} \\
\left(\mathrm{~m}^{2} / \mathrm{g}\right)\end{array}$} & \multirow{2}{*}{$\begin{array}{c}V_{\text {total }} \\
(\mathrm{mL} / \mathrm{g})\end{array}$} & \multirow{2}{*}{$\begin{array}{l}V_{o s} \text { micro } \\
(\mathrm{mL} / \mathrm{g})\end{array}$} & \multirow{2}{*}{ 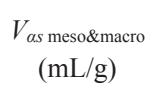 } & \multicolumn{4}{|c|}{ Surface functional group (meq./g) } \\
\hline & & & & & & & Carboxylic & Lactonic & Phenolic & Basic \\
\hline $\mathrm{BC}$ & - & 250 & 250 & 0.160 & 0.083 & 0.077 & 0.02 & 0.00 & 0.64 & 0.23 \\
\hline BC-AO- 180 & $86.3^{\mathrm{a})}$ & 325 & 339 & 0.170 & 0.123 & 0.047 & 0.14 & 0.00 & 0.83 & 0.00 \\
\hline BC-AO-280 & $84.7^{\mathrm{a})}$ & 327 & 339 & 0.162 & 0.120 & 0.042 & 0.26 & 0.00 & 0.86 & 0.00 \\
\hline BC-AO-380 & $75.8^{\mathrm{a})}$ & 589 & 680 & 0.313 & 0.124 & 0.189 & 1.19 & 0.40 & 2.30 & 0.00 \\
\hline BC-AO-180-OG & $88.3^{\mathrm{b})}$ & 178 & 189 & 0.121 & 0.044 & 0.077 & 0.00 & 0.00 & 0.00 & 0.05 \\
\hline BC-AO-280-OG & $87.5^{\mathrm{b})}$ & 258 & 283 & 0.147 & 0.085 & 0.062 & 0.00 & 0.00 & 0.00 & 0.09 \\
\hline BC-AO-380-OG & $86.8^{\mathrm{b})}$ & 669 & 750 & 0.350 & 0.213 & 0.137 & 0.05 & 0.00 & 0.09 & 0.12 \\
\hline
\end{tabular}

BC: Bamboo Charcoal, BC-AO-T: Bamboo Charcoal Air-Oxidized at $T{ }^{\circ} \mathrm{C}, \mathrm{BC}-\mathrm{AO}-T$-OG: Bamboo Charcoal Air-Oxidized at $T{ }^{\circ} \mathrm{C}$ and Outgassed at $1000{ }^{\circ} \mathrm{C}$, a): yield of Air-Oxidized, ${ }^{\text {b) }}$ : yield of Outgassed, $\alpha s: \alpha_{s}$-plot, micro: micropore, meso\&macro: mesopore and macropore

cluded in the prepared bamboo charcoals $(\mathrm{BC})^{23)}$. The ash in the charcoals includes much amount of potassium, which accounts for approximately $80 \%$ or more in the total contents. Dinnebier et al. indicated that potassium was present as the form of oxalates and/or carbonates in raw bamboo, and that most of them changed into the carbonates in the process of carbonization at $500{ }^{\circ} \mathrm{C}$ and 2 hours ${ }^{24)}$. Therefore, it could be assumed that ash in the bamboo charcoals includes much potassium as the form of potassium carbonates $\left(\mathrm{K}_{2} \mathrm{CO}_{3}\right)$. Wakisaka et al. ${ }^{17)}$ and Haiping et al. ${ }^{25)}$ reported the effect of potassium for the carbonization of activated carbons, and found that potassium could promote the activation with considerable developments of both surface area and pore volume. In this study, the highest content of potassium was observed in the ash of bamboo charcoals, thereby significant developments of surface area and pore volume could be expected for the air oxidation treatment.

In Table 4 were tabulated the surface area, pore volume and the amount of surface functional groups for the bamboo charcoals (BC) and for the air-oxidized bamboo charcoals at $280{ }^{\circ} \mathrm{C}$ together with and without de-ashing treatment, described as BC-DA-AO-280 and BC-AO-280, respectively. The de-ashing treatment reduced the ash content of bamboo charcoals (BC) from $3.15 \%$ to $0.01 \%$. The surface functional groups were much introduced for the air-oxidized bamboo charcoals including ash compared to those for the de-ashed charcoals. Also, approximately $22 \%$ of micropore volume ratio was increased by air oxidation treatment, implying the correlation between the development of pores and the amount of functional groups.

Although a part of ash contents including potassium might be released in the washing process of bamboo chips, the enhancements of surface area and pore volume could be seen for the charcoals carbonized after washing of bamboo chips as previously shown in Table 2. This would imply that the effects of hydrolysis for several structural components such as hemicelluloses, cellulose and lignin, and also elution of these components into washing solution on the enhancements of surface properties were greater than that of potassium in the carbonization process at $500{ }^{\circ} \mathrm{C}$.

On the contrary, since ash showed positive effects on each surface property in the process of air oxidation, the bamboo charcoals were oxidized at 180,280 and $380{ }^{\circ} \mathrm{C}$ without any treatments for ash removal. The surface area, pore volume and the amount of surface functional groups for the prepared bamboo charcoals were shown in Table 5. The air oxidation treatment at all temperature conditions increased both surface area $\left(S_{\mathrm{BET}}\right.$ and $\left.S_{a s}\right)$ and total pore volume $\left(V_{\text {total }}\right)$ as well as surface functional groups, especially acidic groups. A little increases in the surface area and total pore volume were observed for the oxidation temperatures of both 180 (BC-AO-180) and $280{ }^{\circ} \mathrm{C}$ (BC-AO-280), while the surface area, total pore volume, and mesopore and macropore volume indicated approximately 3 times, 2 times and 2.5 times higher values than those for non-oxidized bamboo charcoals (BC), respectively, at the oxidation temperature of $380{ }^{\circ} \mathrm{C}$ (BC-AO-380). According to the report from Wakisaka et al. ${ }^{17)}$, potassium in bamboo charcoal could significantly lead to the increase in weight loss in $\mathrm{CO}_{2}$ gas activation process. On the other hand, Haiping et al. examined the effect of $\mathrm{K}_{2} \mathrm{CO}_{3}$ on pyrolysis temperature for cellulose, and revealed that $\mathrm{K}_{2} \mathrm{CO}_{3}$ could lower the onset temperature for pyrolysis ${ }^{25)}$. The air oxidation temperatures in this study were apparently lower than that for carbonization, therefore the develop- 


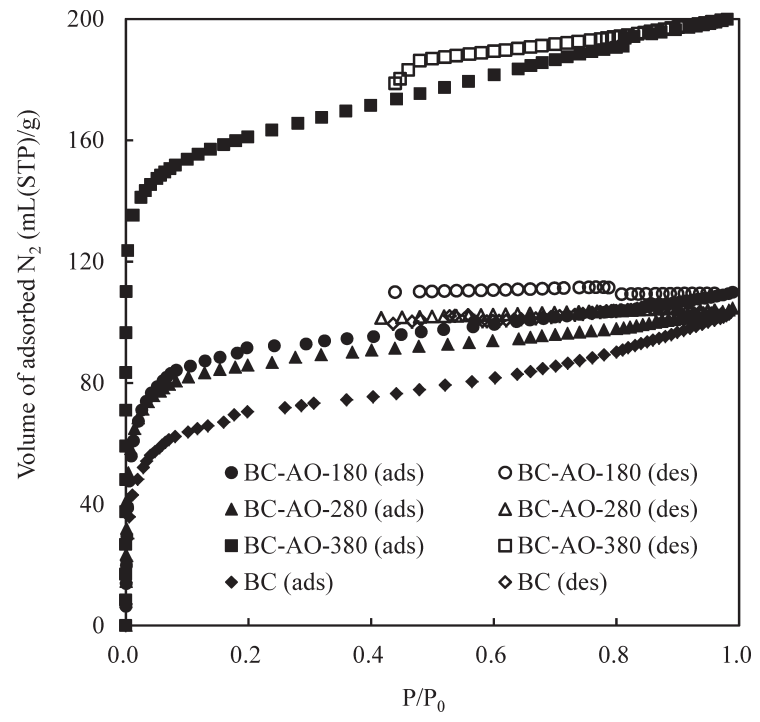

Fig. 2 Nitrogen adsorption-desorption isotherms for BC series. BCAO-T: Bamboo Charcoal Air-Oxidized at $T^{\circ} \mathrm{C}$, ads: adsorption, des: desorption.

ments of surface area and total pore volume, especially oxidation temperature of $380^{\circ} \mathrm{C}$, would be due to the lowered onset temperature for the pyrolysis as suggested by Haiping et al. ${ }^{25)}$.

Fig. 2 displayed the $\mathrm{N}_{2}$ adsorption-desorption isotherms obtained in the measurements of surface area and pore volume for the bamboo charcoal (BC) and air-oxidized charcoals (BC-AO-180, -280 and -380). Each of the isotherms clearly exhibited hysteresis. Everett stated that hysteresis in the adsorption-desorption isotherms resulted in the capillary condensation in the mesopore ${ }^{26)}$, implying that the prepared bamboo charcoals would possess the ink bottle-typed pores distributed on the surface ${ }^{27)}$. The air oxidation treatment increased the adsorption amount of nitrogen, whereas the area of hysteresis obtained for each isotherm was gradually decreased with increasing the oxidation temperature. This would be due to that carbon near the entrance of pores was wasted in the process of oxidation, causing the transformation in a form of the ink bottle-typed into the slit-typed or plate-typed pores $^{28)}$.

It is well understood that the air oxidation treatment produces the acidic functional groups on the surface of charcoals ${ }^{29), 30)}$. The results in Table 5, which represent the surface properties and the amount of surface functional groups for the air-oxidized bamboo charcoals, indicate that the carbonized charcoal (BC) possessing some surface area and pore volume will result in the increase in surface functional groups by the air oxidation. This would be attributed to the increased edges of graphite layers accompanying carbonization, which would play an important role for the production of functional groups.

3.3 Surface and pore properties of the outgassed bamboo charcoals

Table 5 also represents the properties of outgassed bamboo charcoals. The surface area and pore volume for bamboo charcoals oxi- dized in air at 180 and $280{ }^{\circ} \mathrm{C}$ and then outgassed at $1000{ }^{\circ} \mathrm{C}(\mathrm{BC}-$ $\mathrm{AO}-180-\mathrm{OG}$ and $\mathrm{BC}-\mathrm{AO}-280-\mathrm{OG})$ were respectively less than and equal to those of the charcoal before air oxidation (BC). Although both surface area and pore volume for BC-AO-180-OG and -280-OG were decreased, the enhancement of mesopore volume was clearly observed. This would be caused by the unification of micropores accompanying high temperature treatment. The same trends were also expected for BC-AO-380-OG, but the surface area and pore volume were contrarily increased. These reasons would be due to that much more pore-forming sites were present in BC-AO-380-OG compared to $\mathrm{BC}-\mathrm{AO}-180-\mathrm{OG}$ and $-280-\mathrm{OG}$, and that the pore-forming sites caused the production of micropore by outgassing treatment. The discussion for pore-forming sites could be made as follows. In this study, the surface area and pore volume were estimated based on the BET method and the SPE method using $\alpha_{s}$-plot from the result of nitrogen adsorption, which would not reflect the pores of less than $0.7 \mathrm{~nm}$ in diameter to the estimation. These ultra-micropores could be expected as the potential pore-forming sites. In the surface of BCAO-380-OG, there would be a number of ultra-micropores, which would appear with the effect of potassium included in the charcoals in the air oxidation process. BC-AO-180-OG and -280-OG also possess the ultra-micropores, but the amounts would be much less than those for BC-AO-380-OG. The difference in the amount of ultramicropores would be affected by air oxidation temperature (less effect for 180 and $280{ }^{\circ} \mathrm{C}$, much effect for $380{ }^{\circ} \mathrm{C}$ ). The ultra-micropores would be developed to the micropore because of contraction of graphite layers, and the higher proportion of development of micropore than that of mesopore and macropore produced by unification of micropores would cause the developments of surface area and pore volume observed for BC-AO-380-OG.

\subsection{Characteristics of water vapor adsorption and desorption for each prepared bamboo charcoal}

The water vapor adsorption and desorption isotherms for each prepared bamboo charcoal was represented in Fig. 3. In low humidity region below relative humidity $(\mathrm{RH}) 50 \%$, water vapor adsorption was observed for air-oxidized bamboo charcoals (BC-AO-180, -280 and -380 ) possessing the surface functional groups. The amount of water vapor adsorbed on the charcoals was in proportion to the amount of functional groups, representing that the charcoals oxidized at $380{ }^{\circ} \mathrm{C}$ (BC-AO-380) showed approximately twice higher water vapor adsorption than the charcoals treated at 180 and $280^{\circ} \mathrm{C}$ (BC-AO-180 and $\mathrm{BC}-\mathrm{AO}-280)$. Little water vapor adsorption was observed for the charcoals possessing almost no surface functional groups by outgassing treatment at $1000{ }^{\circ} \mathrm{C}$ (BC-AO-180-OG, -280-OG and -380-OG). In low humidity region, the bamboo charcoals hardly adsorb water vapor because of the hydrophobic properties of the charcoals ${ }^{6}$. Accordingly, the water vapor adsorption in low humidity region would be attributed to the hydrogen bond with functional groups rather than 


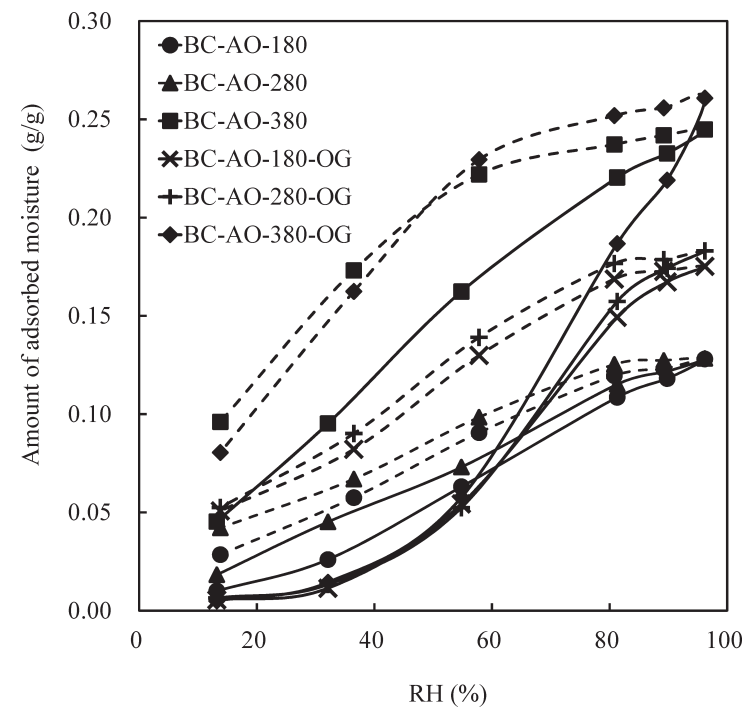

Fig. 3 Water vapor adsorption-desorption isotherms for $\mathrm{BC}$ series. BC-AO-T: Bamboo Charcoal Air-Oxidized at $T^{\circ} \mathrm{C}$, BC-AOT-OG: Bamboo Charcoal Air-Oxidized at $T^{\circ} \mathrm{C}$ and Outgassed at $1000{ }^{\circ} \mathrm{C}$, ads: adsorption (solid line), des: desorption (dashed line).

pores on the surface of bamboo charcoals.

In middle and high humidity regions above RH 50\%, much water vapor adsorption for the air-oxidized bamboo charcoals at $380{ }^{\circ} \mathrm{C}$ was observed similarly to low humidity region. Although the outgassed bamboo charcoals (BC-AO-180-OG, -280-OG and -380-OG) did not adsorb water vapor in low humidity region because of the removal of functional groups, the water vapor adsorption for those charcoals in middle and high humidity regions was observed. Considering the results from the air-oxidized bamboo charcoals, the adsorption of water vapor showed the trend of increase in proportion with the amount of mesopore and macropore volume. In general, the adsorption force for adsorbates increases due to the overlap of potential field between pore wall and adsorbates molecules in the inside of small pore like micropore ${ }^{31)}$. Contrarily, much less adsorption force would be expected in the inside of large pore because of a weakness of the force from pore wall ${ }^{6}$. Hence, the amount of water vapor adsorption for the charcoals possessing small pore would be increased in low humidity region, while water vapor adsorption for charcoals possessing large pore would be expected only in high humidity region. This would be due to the possibility of water vapor to access the inside of large pore as the difference in pressure in high humidity region with the aid of capillary condensation. Therefore, water vapor adsorption would be effective for the bamboo charcoals possessing much amount of functional groups in low humidity region. In middle and high humidity regions, the pore rather than functional groups on the charcoals would be favorable to adsorb water vapor. Each of adsorption and desorption isotherm showed hysteresis. The hysteresis would be caused by capillary condensation in pore on the charcoals. The similar trend could be found in the reports by Everett ${ }^{26)}$.

\section{Conclusions}

In this study, the bamboo charcoals were prepared by the low temperature carbonization at $500{ }^{\circ} \mathrm{C}$, and the various treatments such as the air oxidation and outgassing for introduction and for removal of functional groups on the surface, respectively, were conducted to examine the relationship between the amount of water vapor adsorption and the surface properties of the prepared charcoals. The conclusions can be summarized as follows.

(1) The air oxidation treatment of the bamboo charcoal could develop surface area and pore volume as well as surface functional groups, and pronounced advances could be seen between 280 and $380^{\circ} \mathrm{C}$.

(2) The air oxidation at $380{ }^{\circ} \mathrm{C}$ could enhance surface area from $250 \mathrm{~m}^{2} / \mathrm{g}$ to $590 \mathrm{~m}^{2} / \mathrm{g}$ and pore volume from $0.16 \mathrm{~mL} / \mathrm{g}$ to 0.31 $\mathrm{mL} / \mathrm{g}$.

(3) In the outgassing treatment at $1000{ }^{\circ} \mathrm{C}$, the surface area and pore volume were developed for BC-AO-380-OG, but decreased for both $\mathrm{BC}-\mathrm{AO}-180-\mathrm{OG}$ and $-280-\mathrm{OG}$. These trends would be attributed to the existence of pore-forming sites for the production of micropore.

(4) The charcoals oxidized at $380{ }^{\circ} \mathrm{C}$ enabled to adsorb approximately twice amounts of water vapor compared to those oxidized at 180 and $280{ }^{\circ} \mathrm{C}$ in low humidity region below $\mathrm{RH} 50 \%$, implying that the water vapor adsorption would be controlled by the surface functional groups.

(5) In middle and high humidity region above $\mathrm{RH} 50 \%$, the outgassed bamboo charcoals were favorable for water vapor adsorption, implying that mesopore and macropore rather than surface functional groups played a main role for water vapor adsorption.

\section{Acknowledgements}

This study was partly supported by Grants-in-Aid for Scientific Research (C) (No.23510091) from Japan Society for the Promotion of Science (JSPS). The authors wish to express gratitude to Prof. Dr. Keiichi Nagao, Head of Safety and Health Organization, Chiba University, for his encouragement and support on this work. Gratitude is also extended to Prof. Dr. Masami Aikawa of Kisarazu National College of Technology for his fruitful discussion on the experimental results.

\section{References}

1) T. Matsui, Y. Matsushita, K. Sugamoto, Y. Tokuda, K. Kodama, K. Nakata, M. Oda and H. Yamauchi, Nippon Kagaku Kaishi 2000 53-61 [in Japanese].

2) Y. Matsushita, K. Sugamoto, K. Hidaka and T. Matsui, Nippon Kagaku Kaishi 2002 385-391 [in Japanese].

3) T. Ohgama, Y. Imamura, M. Norimoto, K. Abe and H. Tatsumoto, Moku- 
zai Gakkaishi 51 (2005) 334-339 [in Japanese].

4) M. Yatagai, R. Ito, T. Ohira and K. Oba, Mokuzai Gakkaishi 41 (1995) 425-432 [in Japanese].

5) M. Hitomi, Y. Kera, H. Tatsumoto, I. Abe, I. Kawafune and N. Ikuta, TANSO 1993 [No.160] 247-254 [in Japanese].

6) I. Abe, S. Iwasaki, Y. Iwata, H. Kominami and Y. Kera, TANSO 1998 [No.185] 277-284 [in Japanese].

7) K. Sugamoto, Y. Matsushita, S. Fujimoto and T. Matsui, TANSO 2004 [No.212] 69-74 [in Japanese].

8) I. Abe, S. Iwasaki, K. Asami and J. Senda, TANSO 2003 [No.208] 114119 [in Japanese].

9) I. Abe, T. Hasegawa, Y. Shibutani and S. Iwasaki, TANSO 2004 [No.215] 241-245 [in Japanese].

10) S. Iwasaki, T. Hasegawa, K. Ohya, Y. Shibutani and I. Abe, TANSO 2005 [No.220] 270-275 [in Japanese].

11) A. Nakanishi, M. Tamai, N. Kawasaki, T. Nakamura, M. Araki and S. Tanada, J. Colloid Interface Sci. 255 (2002) 59-63.

12) A. Nakanishi, M. Tamai, N. Kawasaki, T. Nakamura, K. Matsumoto and S. Tanada, Haikibutsu Gakkai Ronbunshi 14 (2003) 69-75 [in Japanese].

13) A. Nakanishi, M. Tamai, S. Tanada, T. Nakamura and N. Kawasaki, Haikibutsu Gakkai Ronbunshi 16 (2005) 13-19 [in Japanese].

14) J. C. Gonzalez, M. Molina-Sabio and F. Rodriguez-Reinoso, Appl. Clay Sci. 20 (2001) 111-118.

15) K. Minami, K. Kawamura and N. Oshima, Nippon Ringakkaishi 40 (1958) 68-79.

16) D. M. Nevskaia, A. Santianes, V. Munoz and A. Guerrero-Ruiz, Carbon 37 (1999) 1065-1074.
17) H. Wakisaka, H. Miyake and Y. Kawahara, TANSO 2006 [No.224] 272275 [in Japanese].

18) D. Lozano-Castello, D. Cazorla-Amoros, A. Linares-Solano, S. Shiraishi, H. Kurihara and A. Oya, Carbon 41 (2003) 1765-1775.

19) H. P. Boehm, Carbon 40 (2002) 145-149.

20) Japanese Industrial Standards Committee, JIS A 1470-1, Japanese Standards Association 2002 [in Japanese].

21) Japanese Industrial Standards Committee, JIS B 7920, Japanese Standards Association 2000 [in Japanese].

22) M. Ota and S. Sugi, The Reports of the Kyushu University Forests (1) (1953) 79-90 [in Japanese].

23) N. Yamashita and M. Machida, Wood Sci. Technol. 45 (2011) 801-808.

24) R. E. Dinnebier, S. Vensky, M. Jansen and J. C. Hanson, Chem. Eur. J. 11 (2005) 1119-1129.

25) Y. Haiping, Y. Rong, C. Hanping, Z. Chuguang, H. L. Dong and T. L. David, Combust. Flame 146 (2006) 605-611.

26) D. H. Everett, The Solid-Gas Interface, Vol. 2 (E. A. Flood, ed.) (1967) pp. 1055-1113, Marcel Dekker, New York.

27) J. W. McBain, J. Am. Chem. Soc. 57 (1935) 699-700.

28) J. H. de Boer, The Structure and Properties of Porous Materials (1958) p. 68, Butterworths, London.

29) C. A. Toles, W. E. Marshall and M. M. Johns, Carbon 37 (1999) $1207-$ 1214.

30) G. G. Stavropoulos, P. Samaras and G. P. Sakellaropoulos, J. Hazard. Mater. 151 (2008) 414-421.

31) D. H. Everett and J. C. Powl, J. Chem. Soc., Faraday Trans. 172 (1976) 619-636. 